ORIGINAL ARTICLE

\title{
Loss of the Birt-Hogg-Dubé tumor suppressor results in apoptotic resistance due to aberrant TGF $\beta$-mediated transcription
}

\author{
TP Cash ${ }^{1,2}$, JJ Gruber ${ }^{1}$, TR Hartman ${ }^{3}$, EP Henske ${ }^{4}$ and MC Simon ${ }^{1,2,5}$ \\ ${ }^{1}$ Abramson Family Cancer Research Institute, Philadelphia, PA, USA; ${ }^{2}$ Department of Cell and Molecular Biology, University \\ of Pennsylvania School of Medicine, Philadelphia, PA, USA; ${ }^{3}$ Department of Medical Oncology, Fox Chase Cancer Center, \\ Philadelphia, PA, USA; ${ }^{4}$ Brigham and Women's Hospital, Harvard Medical School, Boston, MA, USA and ${ }^{5}$ Howard Hughes \\ Medical Institute, University of Pennsylvania, Philadelphia, PA, USA
}

\begin{abstract}
Birt-Hogg-Dubé (BHD) syndrome is an inherited cancer susceptibility disease characterized by skin and kidney tumors, as well as cystic lung disease, which results from loss-of-function mutations in the $B H D$ gene. $B H D$ is also inactivated in a significant fraction of patients with sporadic renal cancers and idiopathic cystic lung disease, and little is known about its mode of action. To investigate the molecular and cellular basis of BHD tumor suppressor activity, we generated mutant Bhd mice and embryonic stem cell lines. BHD-deficient cells exhibited defects in cell-intrinsic apoptosis that correlated with reduced expression of the BH3-only protein Bim, which was similarly observed in all human and murine BHD-related tumors examined. We further demonstrate that Bim deficiency in $\mathrm{Bhd}^{-1-}$ cells is not a consequence of elevated mTOR or ERK activity, but results instead from reduced Bim transcription associated with a general loss of TGF $\beta$ mediated transcription and chromatin modifications. In aggregate, this work identifies a specific tumor suppressive mechanism for BHD in regulating TGF $\beta$-dependent transcription and apoptosis, which has implications for the development of targeted therapies.
\end{abstract}

Oncogene (2011) 30, 2534-2546; doi:10.1038/onc.2010.628; published online 24 January 2011

Keywords: BHD; apoptosis; Bim; TGF $\beta$; mTOR

\section{Introduction}

Birt-Hogg-Dubé (BHD) syndrome is a rare inherited cancer susceptibility disease characterized by benign hair follicle tumors and lung cysts in a majority of patients, and renal cell carcinoma (RCC) in approximately one third of diagnosed BHD cases (Schmidt et al., 2005). Genetic analyses of families affected by BHD syndrome previously identified germline mutations in the $B H D$ gene on chromosome $17 \mathrm{p} 11.2$, most of which were predicted to prematurely truncate the encoded protein (Nickerson et al., 2002; Toro et al.,

Correspondence: Dr MC Simon, 451 BRB II/III, 421 Curie Boulevard, Philadelphia, PA 19104, USA.

E-mail: celeste2@mail.med.upenn.edu

Received 26 July 2010; revised and accepted 23 November 2010; published online 24 January 2011
2008). Mutational analyses of BHD-related tumors from patients, as well as those from mouse and rat models of BHD syndrome, identified inactivating 'second hits' in the remaining wild-type $B H D$ allele, formally establishing BHD as a tumor suppressor (Okimoto et al., 2004; Vocke et al., 2005; Hasumi et al., 2009). BHD inactivation has also been described in a subset of von Hippel-Lindau-independent RCC syndromes, in approximately one third of sporadic renal cancers, and in $60 \%$ of idiopathic cystic lung disease cases (Khoo et al., 2003; Gunji et al., 2007; Woodward et al., 2008).

While the genetic basis of BHD syndrome is well understood, the cellular and molecular mechanisms involving the protein encoded by $B H D$, also called Folliculin, remain unclear. Dissecting BHD's molecular functions is particularly challenging since the $B H D$ gene product bears no sequence or functional homology to any known protein. Studies in Schizosaccharomyces pombe have suggested a role for the putative yeast BHD ortholog in amino-acid homeostasis, while siRNA-mediated knockdown of Drosophila BHD in the fly has implicated it in male germline stem cell maintenance through Stat and/or BMP signaling (Singh et al., 2006; van Slegtenhorst et al., 2007). Finally, mammalian cell culture analyses and mouse models have linked BHD and mammalian target of rapamycin (mTOR) signaling, potentially mediated through an interaction with its binding partner, called Folliculininteracting protein, and AMP-activated kinase (Baba et al., 2006). These studies demonstrate that BHD loss can paradoxically result in either stimulation or inhibition of mTOR depending on the system examined (Baba et al., 2006, 2009; Hudon et al., 2008, 2010).

To investigate the cellular and molecular mechanisms by which BHD suppresses tumorigenesis, we established $B h d^{-/-}$embryonic stem (ES) cell lines, since the early lethality of $B h d^{-1-}$ embryos precluded the development of other cellular models. We observed that the major cellular consequence of BHD loss is resistance to apoptosis caused by decreased Bim expression. This phenomenon was independent of mTOR and ERK hyperactivation and was instead associated with a general loss of TGF $\beta$-dependent chromatin modifications and transcription. These data present new insight into how BHD functions as a tumor suppressor and 
suggest novel targeted therapeutics for BHD syndrome, sporadic RCC, and cystic lung disease.

\section{Results}

Homozygous mutant Bhd embryos die during early embryogenesis

To define the basic molecular functions of BHD, we initially attempted to establish mouse embryonic fibroblasts from a gene-trap mouse model. In order to fully characterize this mutant Bhd allele (denoted as $m$ ), we mapped the insertional position of the trap cassette to intron 8 of the murine Bhd gene, and established Southern and PCR-based genotyping assays to discriminate wild type from the $m$ allele (Figures $1 \mathrm{a}-\mathrm{c}$ ). Using multiple quantitative real-time (qRT)-PCR probes, we observed a $40-50 \%$ reduction in Bhd mRNA expression in $B h d^{+/ m}$ ES cells compared with $B h d^{+/+}$ controls by qRT-PCR (Figure 1d), and confirmed expression of the BHD- $\beta$ geo fusion product by staining the ES cells with X-Gal (Figure 1e).

$B h d^{+/ m}$ intercrosses yielded no viable $B h d^{m / m}$ embryos after e7.5; although we were unable to genotype e6.5 embryos, we observed that $\sim 25 \%$ of these were severely abnormal or partially resorbed upon dissection, exhibiting grossly atrophied and disorganized egg cylinders, distorted visceral endoderm and lack of cavitation (Figures 1f and g). This phenotype is consistent with a recently reported embryonic lethal phenotype for an independent mutant Bhd allele (Hasumi et al., 2009).

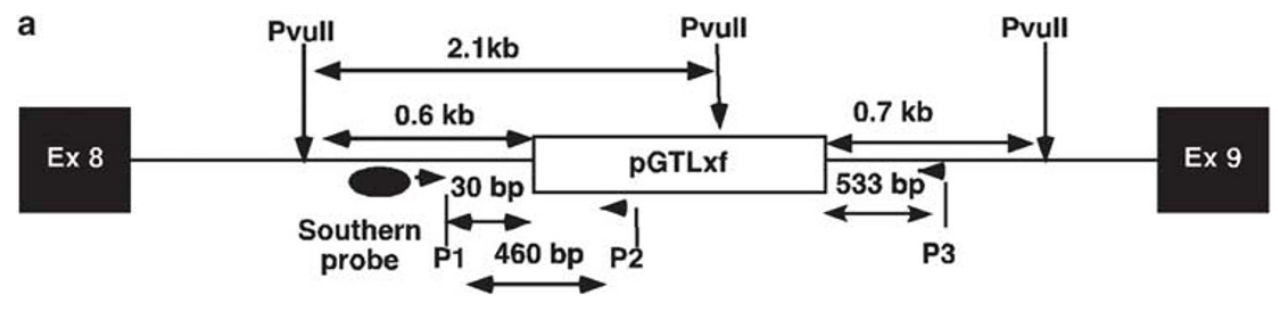

b
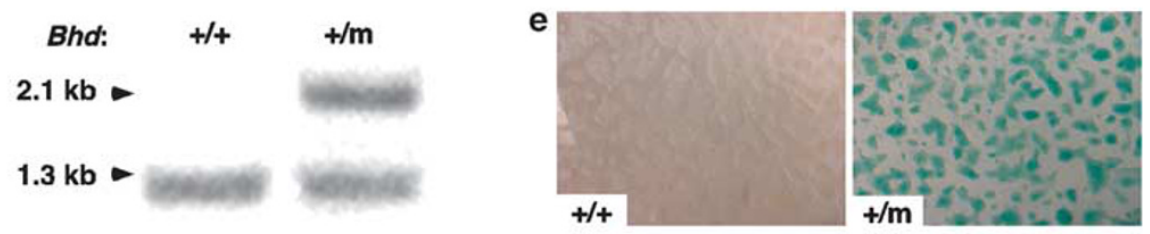

C

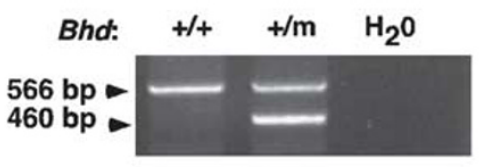

f

\begin{tabular}{|c|c|c|c|}
\hline & $+/ t$ & $+/ m$ & Abnormal \\
\hline e9.5 & $18 \%$ & $50 \%$ & $32 \%$ \\
\hline e7.5 & $19 \%$ & $62 \%$ & $19 \%$ \\
\hline e6.5 & \multicolumn{2}{|c|}{$76 \%{ }^{*}$} & $24 \%^{*}$ \\
\hline
\end{tabular}

d

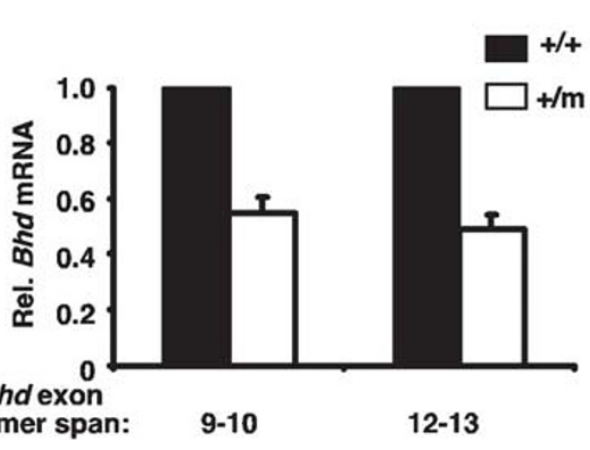

g
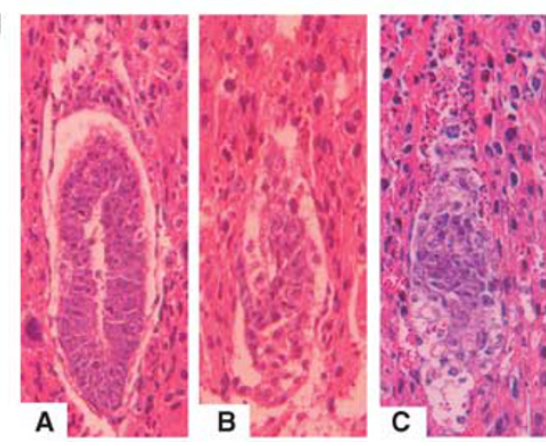

Figure $1 B h d^{m / m}$ embryos are early embryonic lethal. (a) Schematic depicting integration site of Bay Genomics $p G 2 L x f$ gene-trap vector in murine $B h d$ intron 8, location of probe and restriction sites for Southern blot genotyping and location of primers (P1, P2, and P3) for PCR-based genotyping. (b) Southern blot of $P v u I I-d i g e s t e d$ genomic DNA and (c) PCR-based genotypes of $B h d^{+/+}$or $B h d^{+/ m}$ ES cells to discriminate wild-type from mutant alleles. ' $m$ ' specifically designates the gene-trapped mutant $B h d$ allele from Bay Genomics throughout the manuscript. (d) Relative $B h d$ mRNA levels in $B h d^{+/+}$versus $B h d^{+/ m}$ ES cells assayed by qRT-PCR using primers spanning exons just downstream of the trap cassette (exons 9-10) or across the terminal exons of the Bhd gene (exons 12-13), ruling out the presence of aberrant transcripts generated from cryptic transcriptional start sites downstream of the trap cassette. (e) X-Gal staining of $B h d^{+/+}$and $B h d^{+/ m}$ ES cells showing Bhd ${ }^{+/ m}$ cells express the Bhd- $\beta$-galactosidase fusion product. (f) Table of progeny obtained from $B h d^{+/ m}$ intercrosses showing no $B h d^{-/-}$embryos could be recovered after e6.5. (g) $200 \times$ images of H\&E-stained cross-sections of paraffin-embedded e6.5 embryos from $B h d^{+/ m}$ intercrosses. (A) Exemplifies normal morphology while (B) and (C) demonstrate gross abnormalities, probable $B h d^{m / m}$ genotypes. 
Loss of BHD does not affect proliferation, but results in decreased cellular size and resistance to cell-intrinsic apoptosis

Since the early lethality of the $B h d^{m / m}$ embryos precluded the development of differentiated cell types, we generated an ES cell model for in vitro studies. To do this, we used an independent mutant Bhd allele (denoted as '-') with a gene trap in Bhd intron 1, which ablated expression of the entire $B h d$ open reading frame. The $B h d^{+/-}$ES cells were characterized in the same manner as the $B h d^{+/ m}$ cells to validate efficacy of the trap cassette (Supplementary Figures 1a-e).

$B h d^{-1-}$ ES cells were generated from the parental $B h d^{+/-}$ cells as shown by PCR, and western blot confirmed complete loss of BHD protein expression (Figures 2a and b). To verify BHD loss did not affect the undifferentiated state of $B h d^{-/}$ES cells, we analyzed protein levels of Oct-4, Nanog, Sox2 and phospho-Stat3, and alkaline phosphatase activity in $B h d^{+/+}, B h d^{+/-}$, and $B h d^{-1-}$ cells (Supplementary Figures $2 \mathrm{a}-\mathrm{c}$ ). We observed no difference in all parameters of ES cell pluripotency, allowing for valid comparison in in vitro studies across genotypes.

To gain insight into BHD's tumor suppressive properties, we assessed $B h d^{+/+}, B h d^{+/}$, and $B h d^{-1-}$ ES cell lines for proliferation, cell growth, and apoptotic responses. $B h d^{-/-}$ES cells did not proliferate significantly faster at days 1-3 after plating, but confluent cultures analyzed at day 4 were found to contain 15-20\% more cells compared with $B h d^{+/+}$and $B h d^{+/-}$counterparts (Figure 2c). Intriguingly, this difference was attributed to a $15-20 \%$ decrease in cellular volume in $B h d^{-/}$cells (Figure 2d).

Finally, we evaluated the response of $B h d^{-/}$cells to cell-intrinsic apoptosis by starving cells of serum, glucose,

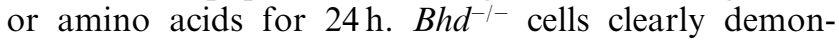
strated a resistance to all three apoptosis-inducing stresses as revealed by light microscopy, decreased accumulation of sub-G1 populations, and reduced Caspase-3 and Parp cleavage (Figures 2e-h). This effect was specific to the intrinsic apoptotic pathway, as $B h d^{-1-}$ cells showed no differential response to the death-receptor ligand Tumor necrosis factor $\alpha$ (Figure $2 \mathrm{~g}$ ). Thus, BHD deficiency does not confer an obvious increase in cellular proliferation or growth, but does reduce cell-intrinsic apoptosis, thereby identifying a plausible cellular role for BHD as a tumor suppressor.

\section{Bim expression is lost in $\mathrm{Bhd}^{-/-}$cells and BHD-related tumors and contributes to apoptotic resistance}

The cell-intrinsic apoptotic resistance of $B \mathrm{Bd}^{-1-}$ cells could either be due to increased intracellular nutrient stores, an effect previously observed in a mutant yeast model of BHD, or result from a defect in the cell-intrinsic death machinery (van Slegtenhorst et al., 2007). To assess the former possibility, we measured levels of 13 different intracellular amino acids by high performance liquid chromatography and observed no differences between $B h d^{+/+}$and $B h d^{-1-}$ ES cells, suggesting that nutrient homeostasis was not playing a role in the apoptoticresistance phenotype (Figure 3a).
To determine if the cell-intrinsic death machinery might be impaired in $B h d^{-/-}$ES cells, we examined protein levels of several Bcl2 family members and found many pro-apoptotic $\mathrm{BH} 3$-only proteins to be misregulated in $B h d^{-1-}$ cells. Both extra-long (EL) and long (L) isoforms of Bim, as well as Puma $\alpha$ and Bad were significantly downregulated in $B h d^{-1-}$ ES cells, while Bid and BMF levels were upregulated (Figure 2b). Bik, Noxa, and Puma $\beta$, as well as the multi-domain Bcl2 family members BclXL and Bak were unchanged. Similar results were obtained using three independent BHD-deficient ES clones homozygous for the $B h d^{m}$ allele (Supplementary Figures $3 \mathrm{a}$ and b). We focused primarily on Bim regulation in subsequent experiments, given its dominant role among BH3-only proteins in mediating the cell-intrinsic death response and frequent loss in RCC (Kim et al., 2006; Zantl et al., 2007; Guo et al., 2009).

To test whether the apoptotic resistance of $B h d^{-1-}$ cells was Bim dependent, we restored either BimEL or $B h d$ expression by retroviral transduction in $B h d^{-1-}$ cells. Restoration of BimEL or Bhd expression, or treatment of cells with the BH3-only chemical mimetic ABT-737, rescued the apoptotic response of $B h d^{-1-}$ ES cells to amino-acid deprivation, as assessed by FACs analysis (Figure 3c, upper panel), and Parp and Caspase-3 cleavage (Figure 3c, lower panel). Importantly, Bhd reconstitution was sufficient to restore Bim protein levels. Interestingly, autophagy inhibitors 3-methyladenine and chloroquine rescued the apoptotic response in $B h d^{-1-}$ cells (Figure 3c), similar to apoptosis-deficient $\mathrm{Bax}^{-1-} \mid \mathrm{Bak}^{-/-}$double knockout cells (Lum et al., 2005).

To determine whether loss of BHD results in Bim deficiency in vivo, we performed immunohistochemistry on BHD-related tumors from both human BHD patients and aged $B h d^{+/ m}$ mice. 3/3 human-derived tumors (one fibrofolliculoma, one chromophobe-clear cell hybrid RCC, and one chromophobe RCC) and 5/5 solid murine renal tumors (four hybrid oncocytic and one papillary mass projecting from a cyst), exhibited absent or significantly reduced Bim expression, confirming that loss of Bim expression is a common event in BHD-related tumors of diverse histologies (Figure 3d).

Bim is transcriptionally downregulated in $\mathrm{Bhd}^{-/-}$ cells independent of mTORC1, mTORC2, ERK, or GCN2-eIF $2 \alpha$ pathway aberrations

Bim is regulated transcriptionally by several wellcharacterized signal transduction pathways, translationally by miRNAs, and on the level of protein stability (Dijkers et al., 2000; Dehan et al., 2009; Su et al., 2009). We initially assessed Bim mRNA and found it to be decreased by $\sim 80 \%$ in $B h d^{--}$cells compared with $B h d^{+/+}$and $B h d^{+/-}$cells (Figure 4a). To investigate a possible additional role for enhanced proteolytic degradation of Bim, we treated $B h d^{-1-}$ cells with the proteasome inhibitor MG-132, but observed no increase in Bim protein (Supplementary Figure 4a) (Dehan et al., 2009). We also examined levels of mir-19 and mir-92, 
a

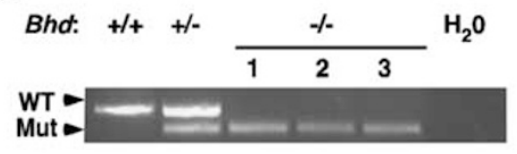

b

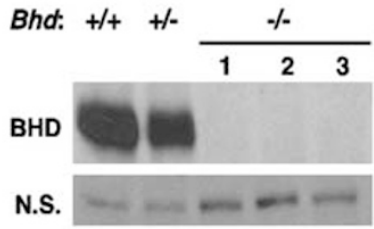

C
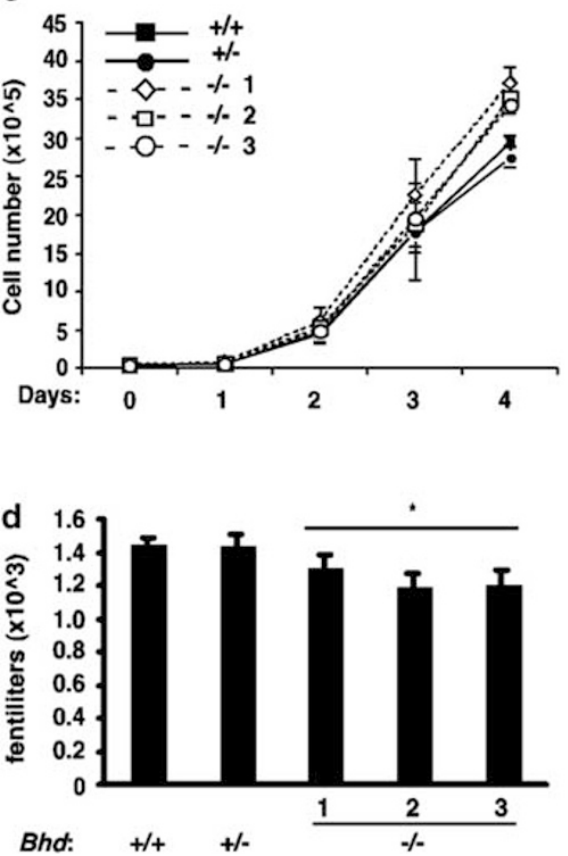
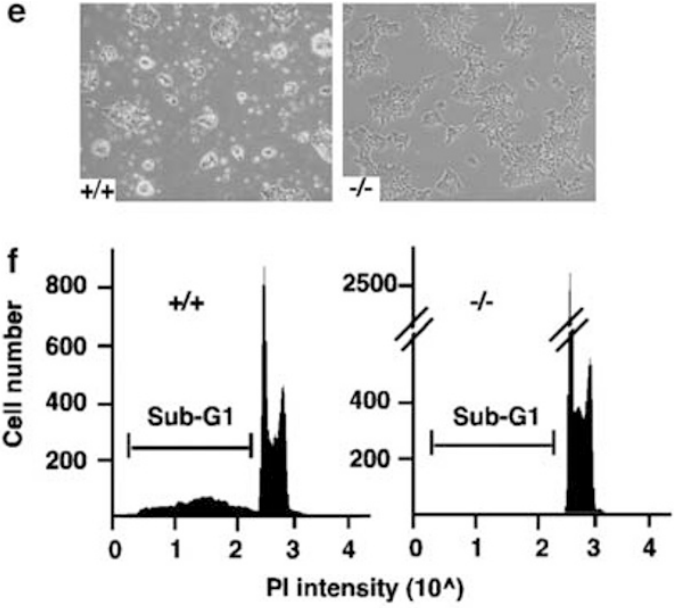

g

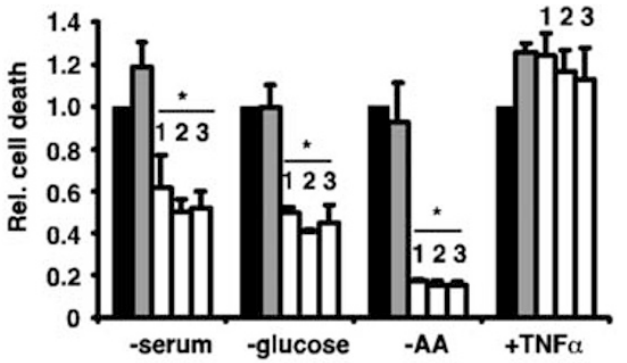

h

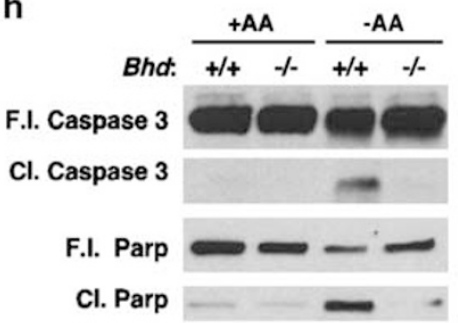

Figure $2 B h d^{-/}$ES cells do not have a proliferative or growth advantage, but are resistant to apoptosis. (a) PCR genotypes verifying loss of wild-type Bhd allele in three independent ES clones, designated as '1', '2', and '3,' after step-up selection. WT=wild-type, Mut $=$ mutant alleles. (b) Western blot demonstrating loss of BHD protein expression in three independent Bhd ${ }^{-1-}$ ES clones with a non-specific (NS) band shown as a loading control. (c) Growth curve showing $B h d^{-/-}$ES cells proliferate at similar rates to $B h d^{+/+}$and $B h d^{+/-}$counterparts, but have increased saturation density at day 4. (d) Coulter counter size measurements showing Bhd $d^{-1-}$ cells are significantly smaller than $B h d^{+/+}$and $B h d^{+/-}$ES cells $(* P=0.000623)$. Bhd $d^{-/-}$ES cells are resistant to stress-induced apoptosis as shown by (e) brightfield images of $B h d^{+/+}$and $B h d^{-1}$ ES cells starved of amino acids for 1 day, or (g) FACs analysis of cells containing sub-G $\mathrm{G}_{1}$ DNA content after 1 day serum, glucose and amino-acid (AA) deprivation compared with $B h d^{+/+}$and $B h d^{+/-}$cells $\left({ }^{*} P<0.0000345\right)$, but not by Tumor necrosis factor $\alpha$ treatment. (f) Representative FACs plot showing Bhd ${ }^{-1-}$ ES cells have significantly less sub-G G $_{1}$ DNA content following 1 day of amino-acid starvation. (h) Western blot of Caspase and Parp cleavage with and without amino-acid starvation in $B h d^{+/+}$and $B h d^{-/-}$ES cells. All bar graphs represent averages of three independent experiments with error bars showing standard error of the mean (s.e.m.).

miRNAs previously shown to regulate Bim translation in ES cells ( $\mathrm{Su}$ et al., 2009), but detected no differences between $B h d^{-1-}$ and control cells (Supplementary Figure 4b).

To determine which transcriptional networks and upstream signaling pathways were involved in Bim misregulation, we investigated the mTOR and ERK pathways that have previously been linked to Bim regulation (Dijkers et al., 2000; Dehan et al., 2009), and are hyperactivated in late-stage cysts and tumors derived from a mutant Bhd mouse model (Baba et al., 2008). Western blot analysis of $B h d^{+/+}, B h d^{+/-}$, and $B h d^{-1-}$ ES cells revealed that $B h d^{-1-}$ ES cells exhibited hyperphosphorylation of S6K1 and 4E-BP1 (indicative of increased mTOR complex 1 (mTORC1) activity), hyperphosphorylation of Akt and the FoxO family of 


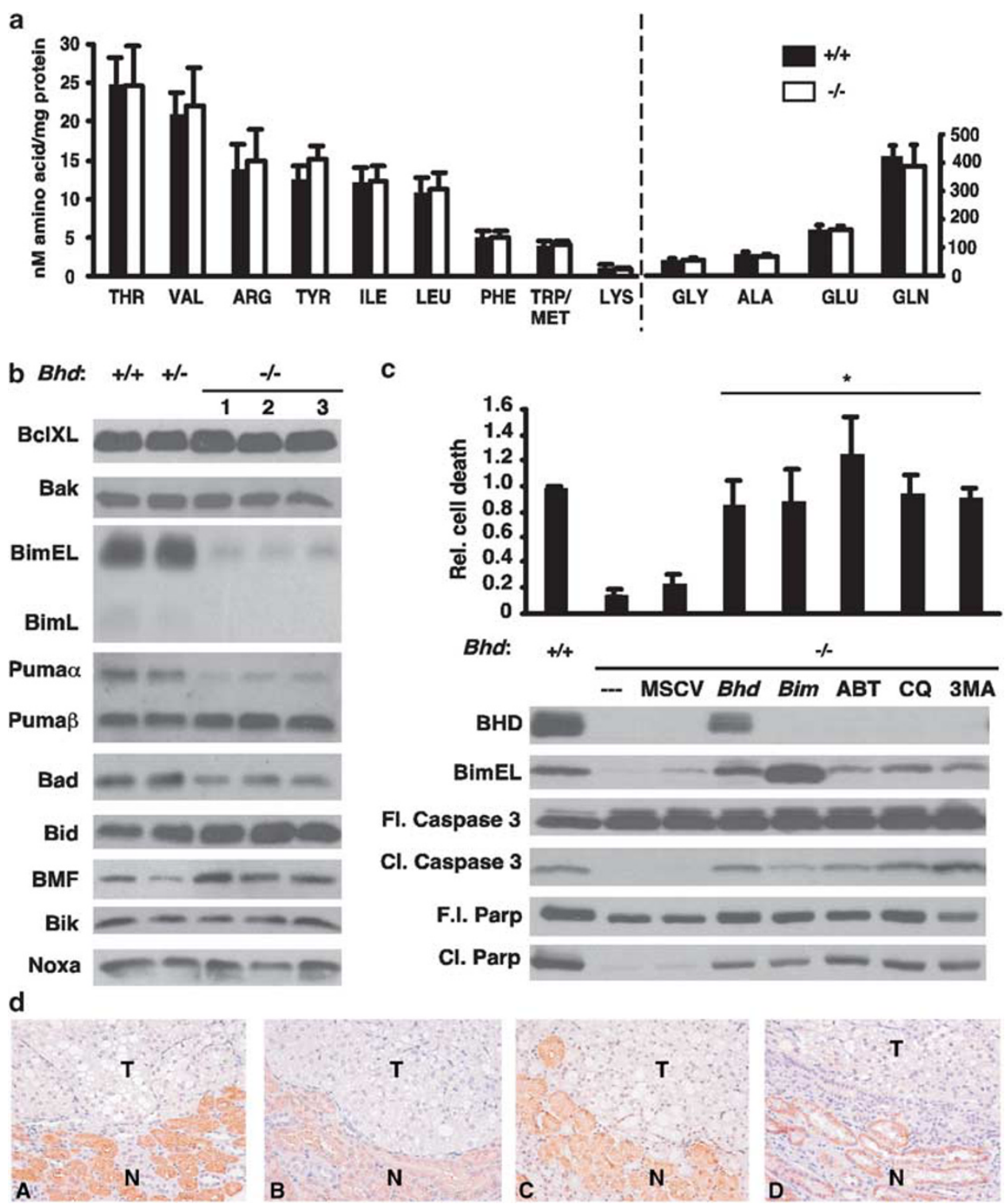

Figure 3 Death resistance of $B h d^{-/-}$cells is not due to increased intracellular amino-acid levels, but instead results from decreased Bim protein levels. (a) Intracellular amino-acid levels normalized to total protein in $B h d^{+/+}$versus $B h d^{-/-}$ES cells as assessed by HPLC. Data represent average of three independent experiments and error bars reflect standard deviation. (b) Western blot showing $B h d^{--}$ES cells have decreased levels of several BH3-only proteins, most notably Bim. (c) Quantification of sub-G $\mathrm{G}_{1}$ populations by flow cytometry in upper panel shows restoration of Bhd and BimEL expression, or treatment with ABT-737 (ABT), chloroquine (CQ) or 3-methyladenine (3MA) rescues the death-resistance phenotype of $B h d^{-1-}$ ES cells in response to 2-day amino-acid starvation compared with untreated or vector only $(M S C V)$ infected controls. Bar graph represents three independent experiments and error bars show s.e.m. Lower panel is a western blot verifying re-expression of BHD and Bim, and correlate changes in Caspase-3 and Parp cleavage. (d) $200 \times$ images of paraffin-embedded sections of solid renal tumors (labeled T) from $B h d^{+/ m}$ mice 18-21 months in age (A-C) or a human patient (D) exhibiting loss of Bim expression compared with normal adjacent tissue (labeled N). (A-C) Hybrid clear celloncocytic lesions from aged $B h d^{+/ m}$ mice and (D) is a human chromophobe RCC.

proteins (indicative of mTOR complex 2 (mTORC2) hyperactivation) and hyperactivation of the MEKERK-p90RSK cascade (Figure 4b).

To determine if these pathways were playing a role in decreased Bim levels in $B h d^{-/-}$cells, we treated cells with inhibitors of each at doses that reduced signaling in $B h d^{-1-}$ cells to levels observed in $B h d^{+/+}$cells. We found that pharmacologic inhibition of PI3K-dependent mTORC2, MEK, or mTORC1 activities, either singly or in combination, was insufficient to restore Bim protein levels in $B h d^{-/-}$cells (Figure 4c). Treatment of $B h d^{-/-}$cells with the same panel of inhibitors was similarly unable to rescue the death-resistance phenotype as assessed by subG1 population quantification (Figure 4d, upper panel), or Caspase and Parp cleavage following 2-day amino-acid starvation (Figure 4d, lower panel).

Bim expression is also known to be regulated by Chop, a transcription factor activated downstream of 


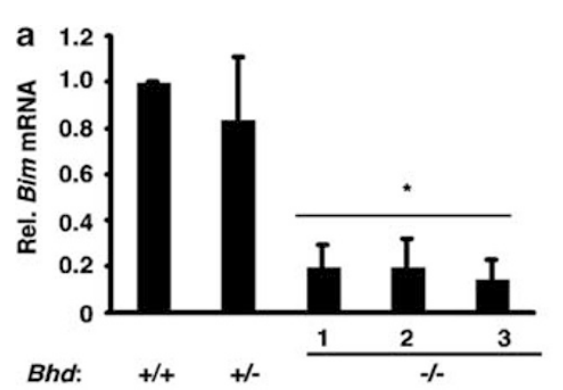

C

b

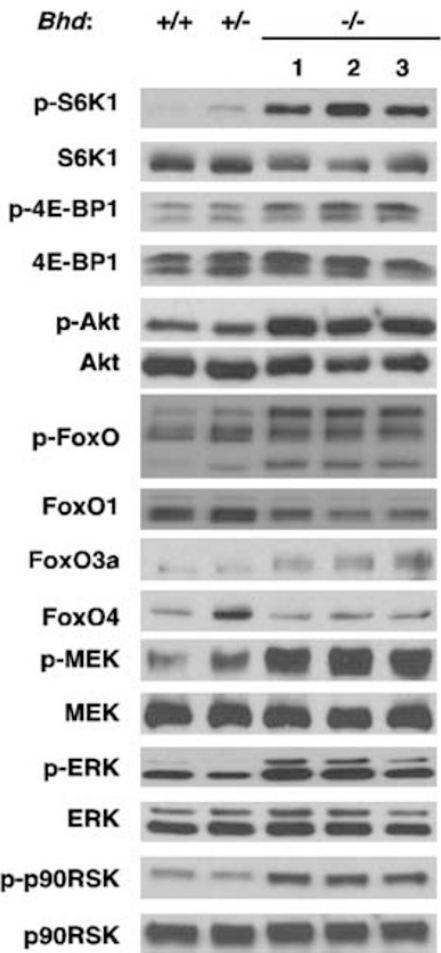

Bhd: + t+ $-$

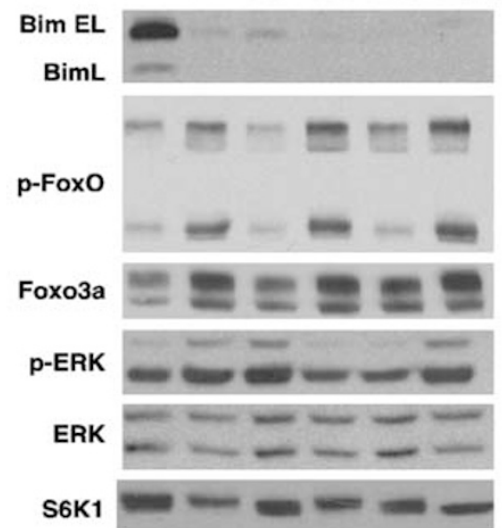

d

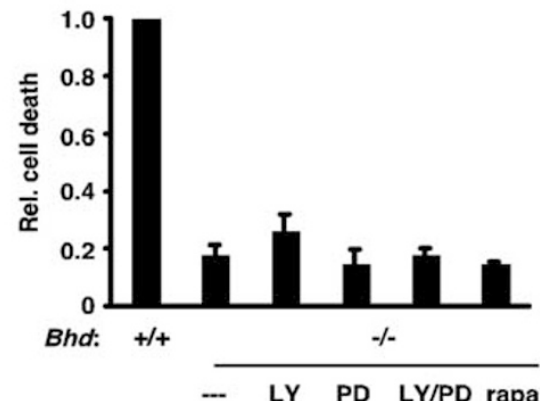

F.I. Caspase 3

Cl. Caspase 3

F.I. Parp

Cl. Parp

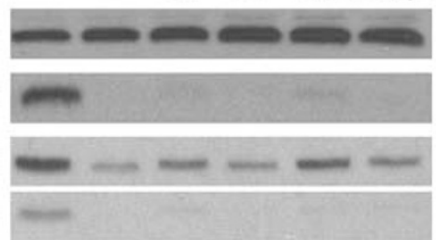

Figure $4 \mathrm{Bim}$ is transcriptionally downregulated in $B \mathrm{~d}^{-/-}$cells independent of mTORC1, mTORC2, or ERK hyperactivation (a) qRT-PCR analysis showing Bim mRNA is reduced in $B h d^{-/-}$ES cells $\left({ }^{*} P=1.44 \times 10^{-7}\right)$. (b) Western blot demonstrating that mTORC1 (indicated by p-S6K1 [T389] and p-4E-BP1 [T70]), mTORC2 (indicated by p-Akt [S473] and p-FoxO [FoxO1 (Thr24]/ FoxO3a [Thr32]/Fox04 [Thr28]) and ERK (indicated by p-MEK [S217/271], p-ERK [T202/Y204], and p-p90RSK [T359/S363]) signaling pathways are hyperactivated in $B h d^{-1-}$ ES cells. (c) Inhibition of hyperactivated mTORC2 by $5 \mu$ M LY294002 (LY) or ERK by $10 \mu \mathrm{M}$ PD98059 (PD) or a combination of both, or inhibition of mTORC1 by $20 \mathrm{~nm}$ rapamycin (rapa) for $24 \mathrm{~h}$ does not restore Bim protein expression levels in $B h d^{-1-}$ cells by western blot. Drug efficacy was shown by decreased p-FOXO levels with LY treatment and decreased p-ERK levels with PD treatment in $B h d^{-/}$cells. Decreased mobility shifts in S6K demonstrate effectiveness of both LY and rapa treatments. Doses were chosen based on their ability to bring activation levels of signaling components in $B h d^{-/-}$cells to those observed in $B h d^{+/+}$cells. (d) $B h d^{-/-}$ES cells were pre-treated for $6 \mathrm{~h}$ with the same panel of inhibitors as (c), then starved of amino acids for 2 days with inhibitors re-added after 1 day of starvation to maintain concentrations. Death was assessed by quantification of sub- $\mathrm{G}_{1}$ populations by flow cytometry (upper panel, $* P<0.0345$ ) and Caspase and Parp cleavage by western blot (lower panel). All bar graphs in this figure represent averages of three independent experiments with error bars reflecting s.e.m.

eukaryotic initation factor $\alpha$ (eIF2 $\alpha)$ kinases as part of the unfolded protein response and as an adaptation to nutrient withdrawal (Puthalakath et al., 2007). Interestingly, $B \mathrm{C}^{-1-}$ cells exhibited decreased basal and aminoacid deprivation-induced levels of p-eIF $2 \alpha$ levels, but not ER stress-induced p-eIF $2 \alpha$ after thapsigargin treatment (Supplementary Figures $5 \mathrm{a}-\mathrm{c}$ ). However, induction of the downstream effectors ATF4 and Chop was only slightly attenuated in response to amino-acid deprivation (Supplementary Figure 5b). More importantly, reintroduction of Chop into Bhd ${ }^{-1-}$ cells failed to rescue Bim expression (Supplementary Figure 5d). Collectively, these data suggest that the downregulation of Bim and apoptotic resistance observed in $B h d^{-1-}$ cells are not due to signaling aberrations in the mTORC1, mTORC2, ERK, and eIF2 $\alpha$ signaling pathways.

Bhd $^{-1-}$ ES cells exhibit many phenotypic and molecular defects characteristic of TGF $\beta$-pathway mutants

We next considered the TGF $\beta$ pathway, since many reports had previously shown it regulated Bim 

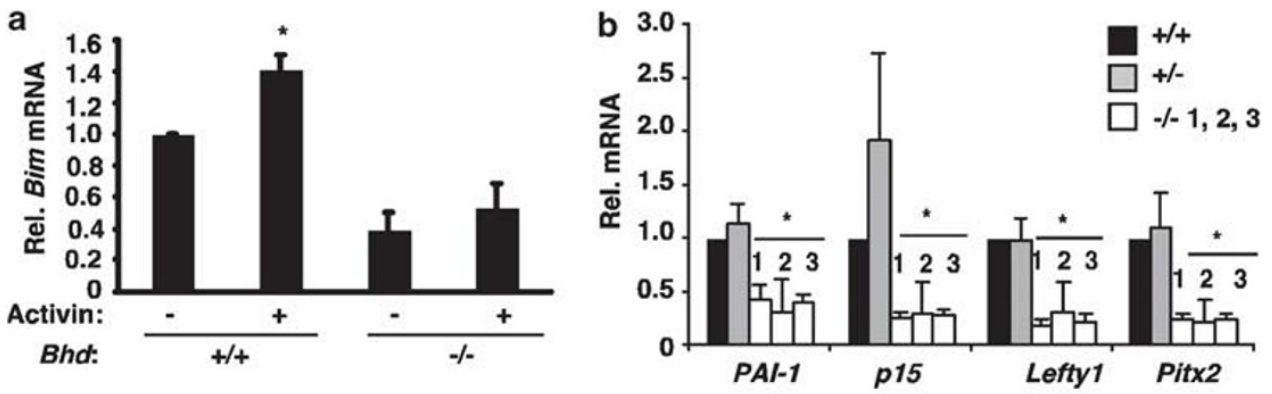

C
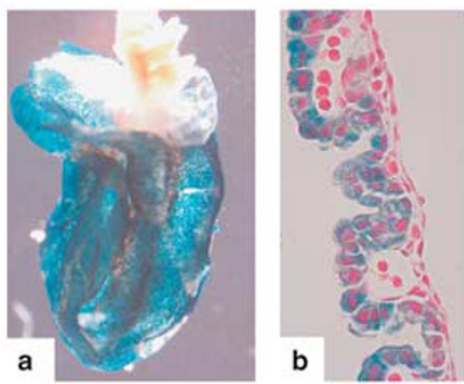

d

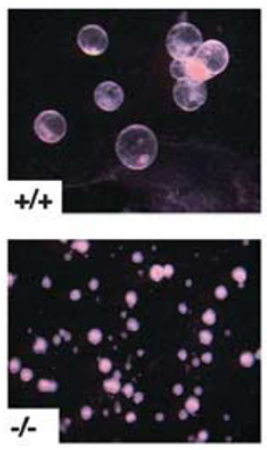

e

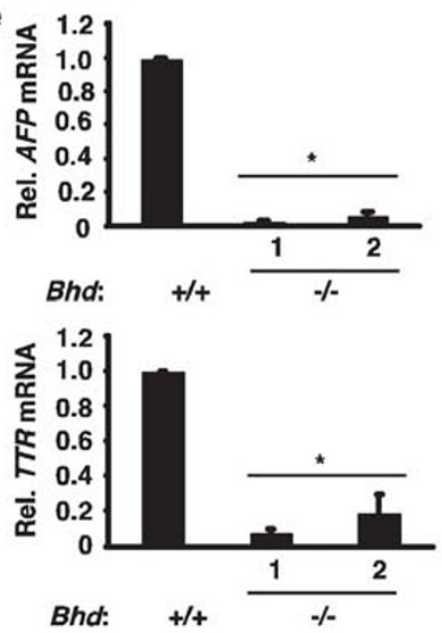

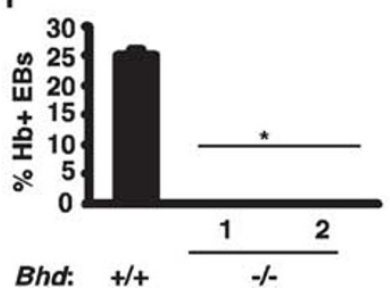

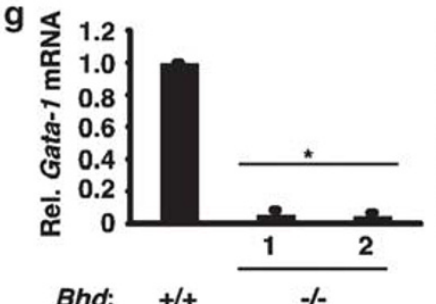

Bhd: $\quad++$

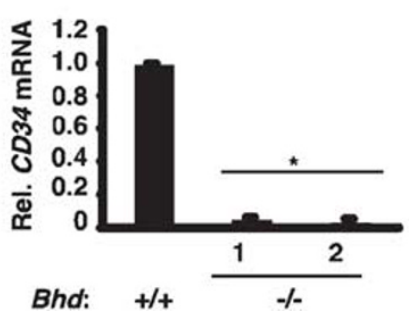

Figure $5 \mathrm{Bhd}^{-/-}$ES cells exhibit phenotypes and transcriptional defects characteristic of TGF $\beta$-signaling components. (a) $B h d^{+/+}$and $B h d^{-1-}$ ES cells were cultured for $24 \mathrm{~h}$ in N2B27 media, then stimulated with $10 \mathrm{ng} / \mathrm{ml}$ of Activin. Bim mRNA levels were significantly induced in $B h d^{+/+}$cells after stimulation, but not in $B h d^{-1-}$ ES cells $\left({ }^{*} P=0.00864\right)$. (b) qRT-PCR analysis showing canonical TGF $\beta$ target genes PAI-1, p15, Leftyl, and Pitx2 are significantly downregulated in multiple $B$ h $^{-1-}$ ES cell clones labeled 1, 2 and 3 $\left({ }^{*} P<0.04\right)$. (c) X-gal stained $70 \times$ image of (a) whole mount or $200 \times$ image of (b) sectioned yolk sac taken from a e10.5 Bhd ${ }^{+/ m}$ embryo exhibiting high $B h d$ expression in visceral endoderm of the yolk sac. (d) $200 \times$ image of day 12 EBs showing Bhd ${ }^{+/+}$EBs form expanded cystic structures reminiscent of yolk sacs while $B h d^{-1-}$ EBs fail to do so. (e) qRT-PCR analysis on RNA from EBs, showing two independent $B h d^{-/}$EBs (clones 1 and 2) fail to express maximal levels of mature yolk sac markers $\alpha$-feto-protein (Afp) and Trithioredoxin (Ttr). Averages represent maximal expression levels for each mRNA, which occurred between days 6 and 9 of EB development $\left({ }^{*} P<1.0 \times 10^{-5}\right.$ for both mRNAs). (f) Quantification of benzediene-positive EBs that express hemoglobin (Hb) at day 10 in methylcellulose cultures demonstrating $B h d^{-1-}$ EBs fail to form erythroid lineages $\left(* P=2.32 \times 10^{-6}\right)$. Data represent the average of three independent experiments with error bars showing standard deviation. (g) qRT-PCR analysis of Gata-1 and CD34 mRNA expression in day $10 \mathrm{EBs}$ in methylcellulose cultures, which is significantly reduced in $\mathrm{Bhd}^{-/-} \mathrm{EBs}\left(P<4.49 \times 10^{-6}\right)$.

transcription in diverse cell types (Wildey et al., 2003; Ramjaun et al., 2007; Ramesh et al., 2008; Yu et al., 2008; Houde et al., 2009). We first verified that the TGF $\beta$ ligand family regulates Bim mRNA in ES cells by treating them with Activin, a TGF $\beta$ family ligand to which ES cells are responsive. Bim mRNA was increased within $2 \mathrm{~h}$ of Activin treatment in $B h d^{+/+}$ES cells, which did not occur in $B h d^{--}$cells (Figure 5a). To ascertain whether this effect was specific to Bim, we analyzed the mRNA levels of several other BH3-only family members in response to Activin. Contrary to Bim, Bid, BMF, and Bad mRNAs were not induced by
Activin in wild-type cells, and actually appeared elevated in $B d^{-1-}$ cells (Supplementary Figure 6a). The latter finding was consistent with increased Bid and BMF protein levels in $B h d^{-/}$cells, but appeared opposite to that of Bad protein levels (Figure 3b). While Puma $\alpha$ mRNA was induced by Activin, this was not BHD dependent as it occurred in both $B h d^{+/+}$and $B h d^{-1-}$ cells (Supplementary Figure 6a). Taken together, these data identify Bim as a specific BH3-only mRNA regulated by TGF $\beta$ in a BHD-dependent manner.

To determine if TGF $\beta$-mediated transcriptional defects were a general phenomenon in $B h d^{-1-}$ cells, we 
examined the basal mRNA levels of several established TGF $\beta$-transcriptional targets involved in diverse biological processes. mRNA levels for the cell cycle regulator p15, pro-apoptotic plasminogen inhibitor activator type I (PAI-1) and Leftyl and Pitx2, which have developmental roles were all lower in $B h d^{-1-}$ cells compared with $B h d^{+/+}$cells (Figure 5b). Other canonical TGF $\beta$ mRNA targets such as SnoN, p21, Colla2, and Lefty 2 were similarly downregulated in $B h d^{-1}$ cells (Supplementary Figure 6b). Other TGF $\beta$ targets previously implicated in cell cycle regulation and apoptosis were unaffected in Bhd ${ }^{-/-}$cells, including Gadd45b and p57, while the death-associated protein kinase was actually upregulated (Supplementary Figure 6c). Overall, these data support a positive role for BHD in TGF $\beta$-mediated transcription that governs biological processes implicated in cancer such as apoptosis, cell cycle, and differentiation.

TGF $\beta$ ligands and receptors are required for normal yolk sac vasculogenesis and embryonic hematopoiesis in vivo, and in ES cell-derived cystic embryoid body (EB) cultures in vitro (Dickson et al., 1995; Oshima et al., 1996; Goumans et al., 1999; Larsson et al., 2001). Interestingly, strong BHD expression was observed in yolk sac visceral endoderm, as revealed by X-Gal staining of E10.5 embryos heterozygous for the $B h d^{m}$ allele (Figure 5c). To investigate whether BHD is required for yolk sac development, we generated day 12 EBs from $B h d^{+/+}$and $B h d^{-/-}$ES cells. $B h d^{-1-}$ ES cells failed to form expanded cystic EBs, which are reminiscent of mature yolk sacs in vivo (Figure 5d), or induce mature yolk sac markers $\alpha$-fetoprotein $(A f p)$ and Trithioredoxin (Ttr) (Doetschman et al., 1985) (Figure 5e). To further evaluate the role of BHD in embryonic hematopoietic stem cell development, we generated $B h d^{+/+}$and $B h d^{-1-}$ EBs in methylcellulose cultures, which promotes the differentiation of hematopoietic lineages. $B h d^{-1-}$ EBs failed to form hemoglobinized colonies at day 10 in culture (Figure 5f; Supplementary Figure 6b) and exhibited severely reduced mRNA levels of the erythroid gene Gata-1 and CD34 (a marker of both hematopoietic and endothelial lineages) (Figure $5 \mathrm{~g}$ ). Interestingly, we observed a delayed induction of the mesodermal marker Brachyury, a super-induction of Fgf-5 and attenuated maintenance of Hnf4 at later stages (Supplementary Figure 7). However, these minor effects are unlikely to explain the dramatic hematopoietic and yolk sac defects of $B h d^{-1-}$ EBs, as maximal induction of these target genes was still robust in $B h d^{-1-} \mathrm{EBs}$, increasing by orders of magnitude.

$\mathrm{Bhd}^{-1-}$ cells exhibit hypo-acetylation of TGF $\beta$ target gene promoters, resulting in their death-resistance phenotype Because BHD deficiency resulted in molecular and phenotypic defects similar to TGF $\beta$ receptor and ligand mutants, we next investigated whether the transcriptional defects occurred at the level of receptor-mediated phosphorylation and nuclear translocation of Smadtranscriptional regulators. Therefore, we examined nuclear levels of phosphorylated and total receptorregulated Smad2 and the common partner Smad4, which form a complex and translocate to the nucleus upon cellular engagement of TGF $\beta$ ligands (Zhang et al., 1996). Western blot analysis did not reveal any differences in basal or Activin-induced nuclear accumulation of phospho-Smad2, total Smad2, or total Smad4 in $B h d^{+/+}$versus $B h d^{-1-}$ ES cells (Figures 6a and b).

Since Smads have previously been shown to activate transcription via acetylation of Histone $\mathrm{H} 3$ at target promoters, we performed chromatin immunoprecipitations for acetylated Histone $\mathrm{H} 3$ at the well-characterized Leftyl promoter (Ross et al., 2006). Whereas $B h d^{+/+}$ES cells demonstrated a significant increase in acetyl-H3 levels at the Leftyl promoter following Activin treatment, $B h d^{-1-}$ cells exhibited no response (Figure 6c). A similar effect was observed at the promoter of $P A I-1$, which has been implicated in the apoptotic response (Kortlever et al., 2006; Lademann and Romer, 2008) (Supplementary Figure 8a). This difference was not due to a global reduction of acetyl-H3 levels, which appeared unaffected based on western blot assays (Figure 6d). To determine whether restoration of acetylated Histone levels rescues $B h d^{-1-}$ cell defects, $B h d^{-/-}$cells were treated with the histone deacetylase (HDAC) inhibitor Trichostatin A (TSA), which restored mRNA levels of multiple TGF $\beta$ target genes (PAI-1, p15, and Bim), Bim protein levels and cell death (Figures 6e and f). TSA appeared to have variable effects on other misregulated $\mathrm{BH} 3$-only proteins in $\mathrm{Bhd}^{-1-}$ cells under nutrient deprivation (Supplementary Figure $8 b$ ). First, nutrient deprivation itself changed protein levels of some BH3-only proteins in $B h d^{-1-}$ cells, with BMF actually decreasing and Bad equilibrating to wild-type levels, in contrast to nutrient replete conditions (Figure 3a). TSA appeared to have no effect on Puma $\alpha$ and Bid levels abundance under nutrient limitation, while it slightly elevated Bad and BMF levels. It seems unlikely, however, that Bad and BMF induction can explain the effects of TSA, given the ability of Bim reexpression alone to completely reverse the phenotype of $B h d^{-1-}$ cells. In summary, BHD loss appears to contribute to apoptotic resistance and TGF $\beta$-dependent transcriptional defects via aberrations in chromatin modifications at target gene promoters including Bim (Figure 7).

\section{Discussion}

To date, the cellular and molecular mechanisms of tumor suppression by BHD have remained elusive. Uncovering BHD protein functions is particularly challenging, given the lack sequence homology to any known protein. In this study, we initially observed that the major cellular consequence of BHD loss is apoptotic resistance due to loss of Bim expression, a phenomenon that can be observed in BHD-related renal tumors. These findings prompted us to ask what signaling pathways and/or transcriptional networks were implicated 


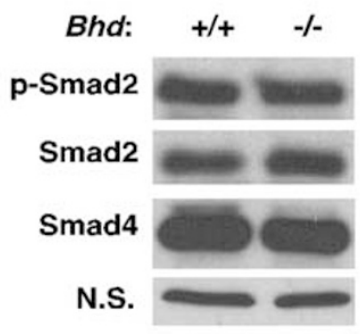

b

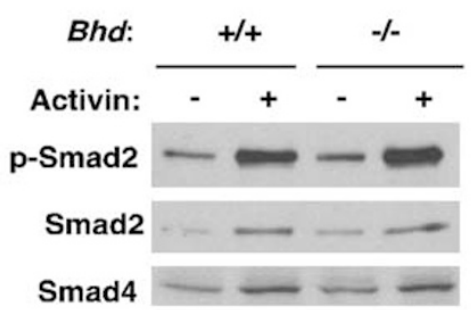

N.S.

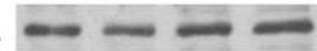

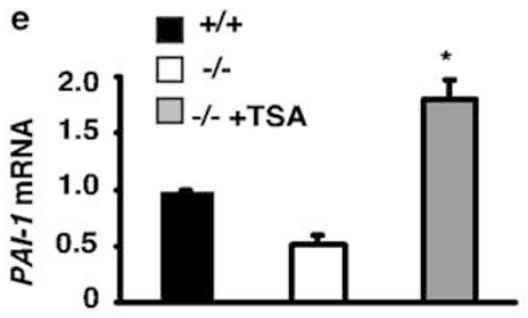
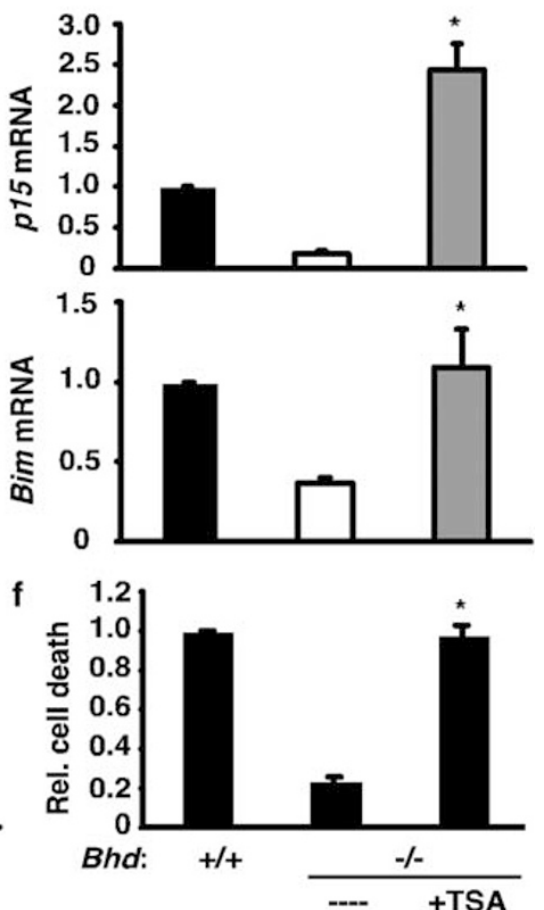

BimEL

F.I. Caspase 3

Cl. Caspase 3

F.I. Parp

Cl. Parp

H3

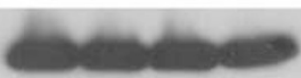

Figure 6 Loss of BHD results in HDAC-mediated silencing of TGF $\beta$-transcriptional targets. Western blot of nuclear extracts showing (a) basal or (b) Activin-induced levels of nuclear phospho-smad2, Smad2, and Smad4 are unaffected in Bhd ${ }^{-/-}$ES cells. Nonspecific (NS) band is shown as a loading control. (c) qRT-PCR using primers located in the Leftyl promoter on genomic DNA immunoprecipitated with acetyl-histone $\mathrm{H} 3$ antibody from ES cells stimulated with activin for $1 \mathrm{~h}$ following $24 \mathrm{~h}$ culture in N2B27. (d) Western blot showing total levels of acetyl-histone $\mathrm{H} 3$ are unaffected in $B h d^{+/+}$versus $B h d^{-1-}$ cells with and without Activin treatment. (e) Treatment of $B h d^{-1-}$ cells with TSA restores mRNA levels of $P A I-1, p 15$, and Bim as shown by qRT-PCR analysis of mRNA expression levels $(* P<0.0362)$. (f) Treatment of $B h d^{-1-}$ ES cells with TSA rescues the $B h d^{-1-}$ cellular death-resistance phenotype and Bim expression as shown by analysis of sub- $\mathrm{G}_{1}$ populations (above, $* P=0.000145$ ) and western blot for Bim, and Caspase and Parp cleavage (below).

in this phenotype. We initially examined the mTOR pathway, as multiple published reports have shown correlations between BHD loss and mTOR activity (Hartman et al., 2009; Hasumi et al., 2009; Hudon et al., 2010). While we did observe aberrant mTOR signaling in $B h d^{-1-}$ cells, this was surprisingly unrelated to the apoptotic defects.

We turned our attention to the TGF $\beta$ pathway, given its known role in regulating Bim transcription and tumor suppression. For instance, in humans, Smad4 germline mutations are associated with juvenile polyposis syndrome, which predisposes individuals to gastrointestinal cancers, and TGF RRI, TGF $R$ RII and activin receptor $I I$ are mutated or downregulated in a broad spectrum of sporadic cancers (Levy and Hill, 2006). Epigenetic silencing of genes involved in TGF $\beta$ signaling has also been specifically observed in RCCs (McRonald et al., 2009). Genetic ablation of these signaling components in mice have confirmed the tumor suppressive function of this pathway in models of colon, mammary, and pancreatic cancer (Massague, 2008). Our data demonstrate that BHD loss results in yolk sac and 

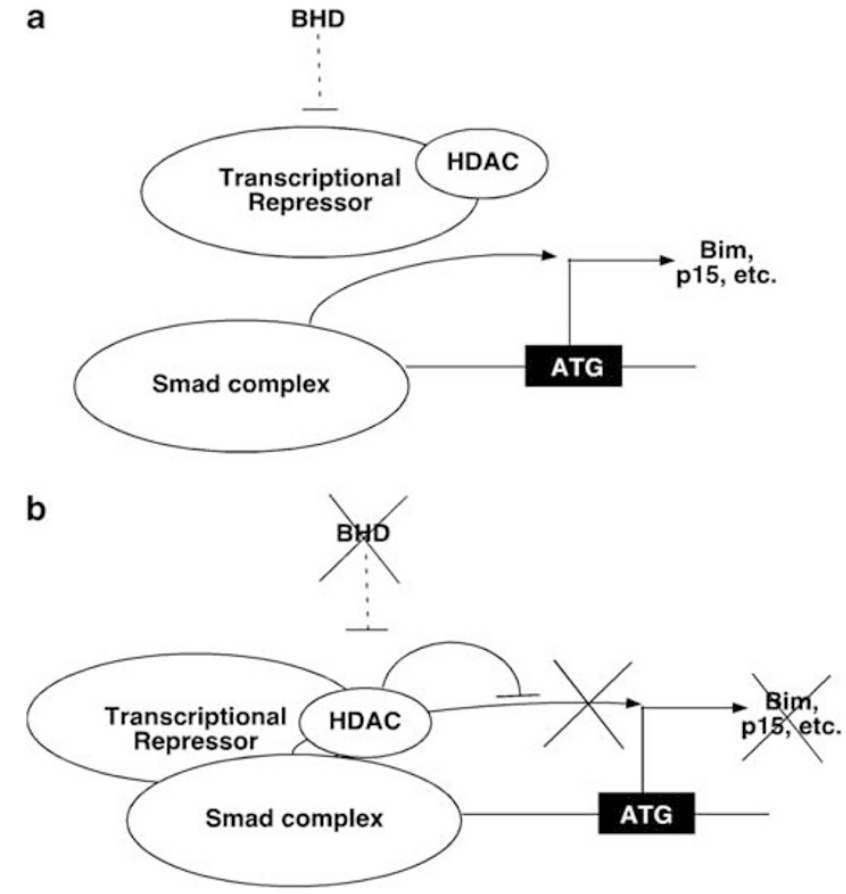

Figure 7 Model: Loss of BHD leads to increased HDACdependent repression of Smad-specific promoters. (a) In the presence of BHD, Smad-dependent transcription is active, allowing transcription of pro-apoptotic genes like Bim and anti-proliferative genes like $p 15$ to promote tumor suppression. (b) However, when BHD is lost, Smad-dependent transcription is repressed and apoptotic and anti-proliferative responses are lost, leading to tumor formation.

hematopoietic defects reminiscent of TGF $\beta$ receptor and ligand mutants. These phenotypes correlate with global aberrations in TGF $\beta$-mediated transcription, which appear to occur downstream of nuclear accumulation of phosphorylated Smads. Our data indicate this defect is most likely due to HDAC-mediated effects on chromatin at Smad-dependent promoters, given the ability of TSA to reverse the biological and molecular defects of $B h d^{-1-}$ cells (Figure 7). Further work will be needed to elucidate the nature of these effects.

Previous studies have suggested a contradictory role for mTOR in BHD-related tumorigenesis, showing that BHD loss can result in either upregulation or downregulation of $\mathrm{mTOR}$ signaling. These studies have been largely correlative and have not demonstrated a causative relationship between the signaling aberrations and biological outcomes (Baba et al., 2006; Hartman et al., 2009; Hasumi et al., 2009; Hudon et al., 2010). While we observed increased mTOR signaling in $B h d^{-1-}$ ES cells, as reported for late-stage kidney tumors taken from a BHD mouse model, this phenomenon appeared unrelated to the observed apoptotic resistance. We speculate that effects of BHD loss on mTOR signaling likely result from compensation and/or crosstalk with more proximal defects in TGF $\beta$ signaling.

Collectively, the data presented here establish a novel model whereby BHD exerts its major tumor suppressive effect through TGF $\beta$-mediated transcriptional output to regulate cell-intrinsic apoptosis. A recent publication has further supported this model, suggesting TGF $\beta$ dependent transcriptional defects in a human BHDderived tumor cell line (Hong et al., 2010). This study demonstrated that BHD deficiency results in decreased levels of TGF $\beta$ pathway signaling components themselves including the ligands TGF $\beta-2$ and Inhibin $\beta$ A and Smad3. This contrasts with our data that demonstrate an effect of BHD downstream of signaling, on canonical Smad target gene promoters. Further, the report by Hong et al. suggested that TGF $\beta-2$ stimulates cell growth and survival in the absence of BHD, while the TGF $\beta$ ligand Activin does the opposite. The latter is surprising in light of our findings, given the failure of BHD null ES cells to mount any transcriptional response to Activin treatment. This discrepancy likely derives from differential cell type, dosage and/or length of treatment, which has been well documented for TGF $\beta$ ligands (Massague, 2008). In any case, these molecular defects likely extend to other tumor-promoting effects such as cell-type specific proliferative advantages, due to p15 loss, and stromal alterations in BHD-related tumors in vivo (Massague, 2008). Although our in vitro study did not uncover a role for BHD in proliferation, this is likely due to the unusual cell cycle machinery of ES cells, which is refractory to cyclindependent kinase inhibitors (Savatier et al., 1996; Faast et al., 2004). It is probable that BHD loss and consequent defective TGF $\beta$-mediated signaling in vivo results in a proliferative advantage. Collectively, these findings suggest several targeted therapeutics for the treatment of BHD-related tumors, as well as sporadic cases of cystic lung disease and RCC, including BH3only mimetics, autophagy inhibitors, and HDAC inhibitors, which are all currently in clinical use for the treatment of other types of cancer.

\section{Materials and methods}

\section{Sub-G $G_{1}$ quantification}

Cells were fixed and stained as previously described, then fluorescence was measured by flow cytometry (Riccardi and Nicoletti, 2006). At least 10000 cells were counted for each experiment and data were analyzed using FlowJo software.

\section{$X$-Gal staining of tissues and embryos}

$\mathrm{X}$-gal staining was carried out as previously described for both cells and whole mount tissues fixed in $4 \%$ paraformaldehyde according to the Sanger Institute gene-trap protocol. $\mathrm{X}$-gal stained yolk sac sections came from tissue snap-frozen in OCT.

\section{Alkaline phosphatase staining}

Cells were stained using the Alkaline Phosphatase Detection Kit from Millipore (Bellerica, MA, USA) according to the manufacturer's instructions.

\section{$R N A$ isolation and $q R T$}

RNA was extracted using Qiagen (Valencia, CA, USA) RNeasy columns with DNAase treatment and cDNA was written off $\sim 1 \mu \mathrm{g}$ of RNA per reaction using the ABI (Foster 
City, CA, USA) one-step RT-PCR Master Mix. qRT-PCR reactions were run in triplicate on an ABI 7900HT machine for each experiment, utilizing either SYBR green or Taqman primer probe sets as noted in Supplementary Materials. All target mRNA levels were normalized to $\beta$-actin or $18 \mathrm{~s}$ expression levels. All qRT-PCR data reflect average mRNA levels from three independent RNA extractions and reverse transcription reactions with error bars showing standard error of the mean.

\section{Protein extraction and western blotting}

Whole-cell lysates were prepared using a buffer containing $120 \mathrm{~mm} \mathrm{NaCl}, 1 \mathrm{~mm}$ EDTA, $10 \mathrm{~mm}$ pyrophosphate, $10 \mathrm{~mm}$ glycerophosphate, $50 \mathrm{~mm} \mathrm{NaF}, 1 \%$ Triton, and freshly added protease inhibitor cocktail tablets from Roche (Basel, Switzerland) and $2 \mathrm{~mm}$ orthovanadate. Nuclear extracts were prepared using the Active Motif Nuclear Extraction kit, with $500 \mathrm{~mm}$ $\mathrm{NaCl}$ added after nuclease digestion followed by sonication of nuclear extracts. Lysates were run on polyacrylamide gels, transferred to nitrocellulose, blotted using standard protocols, and visualized on film using HRP-conjugated secondary antibodies and ECL reagent.

\section{Cell size measurements}

Cell size was measured using a Z2 Coulter particle size analyzer. At least 10000 cells were measured for each experiment.

\section{Characterization of gene-trapped ES cells and mice}

$B h d^{+/ m}$ ES cells were obtained from Bay Genomics and $B h d^{+/-}$ ES cells were obtained from the German Gene Trap Consortium, with isogenic parental $B h d^{+/+}$lines being obtained from each respective source. Gene-trap insertions were mapped by first PCR amplifying the boundary of the fusion transcript using primers within the $3^{\prime}$ end of the trap cassette and within the sequence tag, on cDNA generated from heterozygous ES cells. The precise genomic location of the cassette was mapped by direct PCR amplification of the respective intronic-trap cassette boundary using primers in the exon just upstream from the insertion and within the $5^{\prime}$ end of the trap cassette. Southern blots were carried out on either $P v u I I$ or BamHI-digested DNA on $B h d^{+/ m}$ or $B h d^{+/-}$ES cell, respectively, with $5^{\prime}$ end-directed probes being generated by PCR amplification from genomic DNA and subsequent TOPO cloning. $B h d^{+/ m}$ mice were generated and intercrossed and embryo collection was performed as previously described (Covello et al., 2006; Hartman et al., 2009)

\section{Proliferation assay}

In all, $5 \times 10^{4}$ cells were plated in a gelatinized 12 -well plate and counted using the Countess automatic counter from Invitrogen (Carlsbad, CA, USA) each day after plating.

\section{Immunohistochemistry}

Paraffin-embedded tissue was immunostained using a rabbit polyclonal anti-Bim antibody from Novus following antigen retrieval in sodium citrate solution and developed using diaminobenzidine.

\section{Embryoid bodies}

For suspension cultures, $8 \times 10^{6}$ ES cells were plated in $10 \mathrm{~cm}$ bacterial dishes in DMEM containing $10 \%$ FBS and $\beta$-mercaptoethanol. Media was changed every other day, with EBs being split 1:2 on day 3. Methylcellulose cultures and benezidiene staining were performed as previously described (Cooper et al., 1974; Adelman et al., 1999).

\section{Northern blotting}

Northern blots for miRNAs were done as previously described (Gruber et al., 2009).

\section{Chromatin immunoprecipitation}

In all, $1 \times 10^{6}$ ES cells were fixed for $10 \mathrm{~min}$ in $1 \%$ formaldehyde for $10 \mathrm{~min}$ at room temperature. Crosslinking was quenched with $125 \mathrm{~mm}$ glycine for $5 \mathrm{~min}$, then cells were lysed and sonicated to shear DNA for 3 min with on/off pulses using a Fisher Sonic Dismembranator Model 500 at 20\% power. Chromatin immunoprecipitation was carried using the Imgenex QuikChIP kit according to the manufacturer's instructions using a pan acetyl-H3 antibody from Millipore. Eluted protein/DNA complexes were purified by phenol/ chloroform extraction and ethanol precipitation.

\section{Statistics}

All $P$-values were generated using a two-tailed Student's $t$-test.

\section{Conflict of interest}

The authors declare no conflict of interest.

\section{Acknowledgements}

We thank the Myrovlytis Trust (London, UK) and NIH grant no. CA104838 for funding this work, Marc Yudkoff, Ilana Nissim, Evgueni Daikhin, Hongwei Yu, Anja Runge, and Terri Richardson for technical assistance and Brian Keith, Guoliang Qing, and Xianxin Hua for critically reviewing the manuscript. MCS is an investigator of the Howard Hughes Medical Institute.

\section{References}

Adelman DM, Maltepe E, Simon MC. (1999). Multilineage embryonic hematopoiesis requires hypoxic ARNT activity. Genes Dev 13: 2478-2483.

Baba M, Furihata M, Hong SB, Tessarollo L, Haines DC, Southon E et al. (2008). Kidney-targeted Birt-Hogg-Dube gene inactivation in a mouse model: Erk1/2 and Akt-mTOR activation, cell hyperproliferation, and polycystic kidneys. J Natl Cancer Inst 100: $140-154$.

Baba M, Hong SB, Sharma N, Warren MB, Nickerson ML, Iwamatsu A et al. (2006). Folliculin encoded by the BHD gene interacts

with a binding protein, FNIP1, and AMPK, and is involved in AMPK and mTOR signaling. Proc Natl Acad Sci USA 103: 15552-15557.

Cooper MC, Levy J, Cantor LN, Marks PA, Rifkind RA. (1974). The effect of erythropoietin on colonial growth of erythroid precursor cells in vitro. Proc Natl Acad Sci USA 71: 1677-1680.

Covello KL, Kehler J, Yu H, Gordan JD, Arsham AM, Hu CJ et al. (2006). HIF-2alpha regulates Oct-4: effects of hypoxia on stem cell function, embryonic development, and tumor growth. Genes Dev 20: $557-570$. 
Dehan E, Bassermann F, Guardavaccaro D, Vasiliver-Shamis G, Cohen M, Lowes KN et al. (2009). betaTrCP- and Rsk1/2-mediated degradation of BimEL inhibits apoptosis. Mol Cell 33: 109-116.

Dickson MC, Martin JS, Cousins FM, Kulkarni AB, Karlsson S, Akhurst RJ. (1995). Defective haematopoiesis and vasculogenesis in transforming growth factor-beta 1 knock out mice. Development 121: $1845-1854$

Dijkers PF, Medema RH, Lammers JW, Koenderman L, Coffer PJ. (2000). Expression of the pro-apoptotic Bcl-2 family member Bim is regulated by the forkhead transcription factor FKHR-L1. Curr Biol 10: $1201-1204$

Doetschman TC, Eistetter H, Katz M, Schmidt W, Kemler R. (1985). The in vitro development of blastocyst-derived embryonic stem cel lines: formation of visceral yolk sac, blood islands and myocardium. $J$ Embryol Exp Morphol 87: 27-45.

Faast R, White J, Cartwright P, Crocker L, Sarcevic B, Dalton S. (2004). Cdk6-cyclin D3 activity in murine ES cells is resistant to inhibition by p16(INK4a). Oncogene 23: 491-502.

Goumans MJ, Zwijsen A, van Rooijen MA, Huylebroeck D, Roelen BA, Mummery CL. (1999). Transforming growth factor-beta signalling in extraembryonic mesoderm is required for yolk sac vasculogenesis in mice. Development 126: 3473-3483.

Gruber JJ, Zatechka DS, Sabin LR, Yong J, Lum JJ, Kong M et al. (2009). Ars2 links the nuclear cap-binding complex to RNA interference and cell proliferation. Cell 138: 328-339.

Gunji Y, Akiyoshi T, Sato T, Kurihara M, Tominaga S, Takahashi K et al. (2007). Mutations of the Birt Hogg Dube gene in patients with multiple lung cysts and recurrent pneumothorax. J Med Genet 44: 588-593.

Guo Y, Schoell MC, Freeman RS. (2009). The von Hippel-Lindau protein sensitizes renal carcinoma cells to apoptotic stimuli through stabilization of BIM(EL). Oncogene 28: 1864-1874.

Hartman TR, Nicolas E, Klein-Szanto A, Al-Saleem T, Cash TP, Simon MC et al. (2009). The role of the Birt-Hogg-Dube protein in mTOR activation and renal tumorigenesis. Oncogene 28: 1594-1604.

Hasumi Y, Baba M, Ajima R, Hasumi H, Valera VA, Klein ME et al. (2009). Homozygous loss of BHD causes early embryonic lethality and kidney tumor development with activation of mTORC1 and mTORC2. Proc Natl Acad Sci USA 106: 18722-18727.

Hong SB, Oh H, Valera VA, Stull J, Ngo DT, Baba M et al. (2010). Tumor suppressor FLCN inhibits tumorigenesis of a FLCN-null renal cancer cell line and regulates expression of key molecules in TGF-beta signaling. Mol Cancer 9: 160.

Houde N, Chamoux E, Bisson M, Roux S. (2009). Transforming growth factor-betal (TGF-beta1) induces human osteoclast apoptosis by up-regulating Bim. J Biol Chem 284: 23397-23404.

Hudon V, Sabourin S, Dydensborg AB, Kottis V, Ghazi A, Paquet M et al. (2010). Renal tumor suppressor function of the Birt-HoggDube syndrome gene product folliculin. J Med Genet 47: 182-189.

Khoo SK, Kahnoski K, Sugimura J, Petillo D, Chen J, Shockley K et al. (2003). Inactivation of BHD in sporadic renal tumors. Cancer Res 63: 4583-4587.

Kim H, Rafiuddin-Shah M, Tu HC, Jeffers JR, Zambetti GP, Hsieh JJ et al. (2006). Hierarchical regulation of mitochondrion-dependent apoptosis by BCL-2 subfamilies. Nat Cell Biol 8: 1348-1358.

Kortlever RM, Higgins PJ, Bernards R. (2006). Plasminogen activator inhibitor-1 is a critical downstream target of $\mathrm{p} 53$ in the induction of replicative senescence. Nat Cell Biol 8: 877-884.

Lademann UA, Romer MU. (2008). Regulation of programmed cell death by plasminogen activator inhibitor type 1 (PAI-1). Thromb Haemost 100: 1041-1046.

Larsson J, Goumans MJ, Sjostrand LJ, van Rooijen MA, Ward D, Leveen $\mathrm{P}$ et al. (2001). Abnormal angiogenesis but intact hematopoietic potential in TGF-beta type I receptor-deficient mice. EMBO J 20: 1663-1673.

Levy L, Hill CS. (2006). Alterations in components of the TGF-beta superfamily signaling pathways in human cancer. Cytokine Growth Factor Rev 17: 41-58.

Lum JJ, Bauer DE, Kong M, Harris MH, Li C, Lindsten T et al. (2005). Growth factor regulation of autophagy and cell survival in the absence of apoptosis. Cell 120: 237-248.
Massague J. (2008). TGFbeta in Cancer. Cell 134: 215-230

McRonald FE, Morris MR, Gentle D, Winchester L, Baban D, Ragoussis J et al. (2009). CpG methylation profiling in VHL related and VHL unrelated renal cell carcinoma. Mol Cancer 8: 31 .

Nickerson ML, Warren MB, Toro JR, Matrosova V, Glenn G, Turner ML et al. (2002). Mutations in a novel gene lead to kidney tumors, lung wall defects, and benign tumors of the hair follicle in patients with the Birt-Hogg-Dube syndrome. Cancer Cell 2: $157-164$

Okimoto K, Sakurai J, Kobayashi T, Mitani H, Hirayama Y, Nickerson ML et al. (2004). A germ-line insertion in the BirtHogg-Dube (BHD) gene gives rise to the Nihon rat model of inherited renal cancer. Proc Natl Acad Sci USA 101: 2023-2027.

Oshima M, Oshima H, Taketo MM. (1996). TGF-beta receptor type II deficiency results in defects of yolk sac hematopoiesis and vasculogenesis. Dev Biol 179: 297-302.

Puthalakath H, O'Reilly LA, Gunn P, Lee L, Kelly PN, Huntington ND et al. (2007). ER stress triggers apoptosis by activating BH3-only protein Bim. Cell 129: 1337-1349.

Ramesh S, Qi XJ, Wildey GM, Robinson J, Molkentin J, Letterio J et al. (2008). TGF beta-mediated BIM expression and apoptosis are regulated through SMAD3-dependent expression of the MAPK phosphatase MKP2. EMBO Rep 9: 990-997.

Ramjaun AR, Tomlinson S, Eddaoudi A, Downward J. (2007). Upregulation of two $\mathrm{BH} 3$-only proteins, Bmf and Bim, during TGF beta-induced apoptosis. Oncogene 26: 970-981.

Riccardi C, Nicoletti I. (2006). Analysis of apoptosis by propidium iodide staining and flow cytometry. Nat Protoc 1: 1458-1461.

Ross S, Cheung E, Petrakis TG, Howell M, Kraus WL, Hill CS. (2006). Smads orchestrate specific histone modifications and chromatin remodeling to activate transcription. EMBO $J \mathbf{2 5}$ : 4490-4502.

Savatier P, Lapillonne H, van Grunsven LA, Rudkin BB, Samarut J. (1996). Withdrawal of differentiation inhibitory activity/leukemia inhibitory factor up-regulates D-type cyclins and cyclin-dependent kinase inhibitors in mouse embryonic stem cells. Oncogene 12: 309-322.

Schmidt LS, Nickerson ML, Warren MB, Glenn GM, Toro JR, Merino MJ et al. (2005). Germline BHD-mutation spectrum and phenotype analysis of a large cohort of families with Birt-HoggDube syndrome. Am J Hum Genet 76: 1023-1033.

Singh SR, Zhen W, Zheng Z, Wang H, Oh SW, Liu W et al. (2006). The Drosophila homolog of the human tumor suppressor gene BHD interacts with the JAK-STAT and Dpp signaling pathways in regulating male germline stem cell maintenance. Oncogene 25: 5933-5941.

Su H, Trombly MI, Chen J, Wang X. (2009). Essential and overlapping functions for mammalian Argonautes in microRNA silencing. Genes Dev 23: 304-317.

Toro JR, Wei MH, Glenn GM, Weinreich M, Toure O, Vocke C et al. (2008). BHD mutations, clinical and molecular genetic investigations of Birt-Hogg-Dube syndrome: a new series of 50 families and a review of published reports. J Med Genet 45: 321-331.

van Slegtenhorst M, Khabibullin D, Hartman TR, Nicolas E, Kruger WD, Henske EP. (2007). The Birt-Hogg-Dube and tuberous sclerosis complex homologs have opposing roles in amino acid homeostasis in Schizosaccharomyces pombe. J Biol Chem 282: 24583-24590.

Vocke CD, Yang Y, Pavlovich CP, Schmidt LS, Nickerson ML, Torres-Cabala CA et al. (2005). High frequency of somatic frameshift BHD gene mutations in Birt-Hogg-Dube-associated renal tumors. $J$ Natl Cancer Inst 97: 931-935.

Wildey GM, Patil S, Howe PH. (2003). Smad3 potentiates transforming growth factor beta (TGFbeta)-induced apoptosis and expression of the BH3-only protein Bim in WEHI 231 B lymphocytes. J Biol Chem 278: 18069-18077.

Woodward ER, Ricketts C, Killick P, Gad S, Morris MR, Kavalier F et al. (2008). Familial non-VHL clear cell (conventional) renal cell carcinoma: clinical features, segregation analysis, and mutation analysis of FLCN. Clin Cancer Res 14: 5925-5930. 
Yu J, Zhang L, Chen A, Xiang G, Wang Y, Wu J et al. (2008). Identification of the gene transcription and apoptosis mediated by TGF-beta-Smad2/3-Smad4 signaling. $J$ Cell Physiol 215: 422-433.

Zantl N, Weirich G, Zall H, Seiffert BM, Fischer SF, Kirschnek S et al. (2007). Frequent loss of expression of the pro-apoptotic protein Bim in renal cell carcinoma: evidence for contribution to apoptosis resistance. Oncogene 26: 7038-7048.
Zhang Y, Feng X, We R, Derynck R. (1996). Receptor-associated Mad homologues synergize as effectors of the TGF-beta response. Nature 383: $168-172$.

\section{(c)} (c)

This work is licensed under the Creative Commons Attribution-NonCommercial-No Derivative Works 3.0 Unported License. To view a copy of this license, visit http://creativecommons.org/licenses/by-nc-nd/3.0/

Supplementary Information accompanies the paper on the Oncogene website (http://www.nature.com/onc) 